\section{Australians wait and see}

\section{Canberra}

A GOVERNMENT report on the effects of the British nuclear weapons tests in Australia during the 1950 s has found them to be safe, in line with official statements from the British Ministry of Defence. The longawaited Australian Ionizing Radiation Advisory Committee (AIRAC) review of operational safety measures and possible after-effects was tabled in the House of Representatives on 26 May. That the government is not altogether satisfied is suggested by its decision to await the results of a health survey of all servicemen involved in the tests (see Nature 300, 98; 1982) before deciding what to do.

The main conclusions of the AIRAC report, based on official records, are:

- There is no evidence of any departures from compliance with International Commission on Radiological Protection (ICRP) recommendations.

- No Australian received a radiation dose in excess of the then ICRP recommendations.

- Criteria for safe firing were met.

- There is no evidence that aborigines were injured by tests.

Even Totem 1, the first of the two tests at Emu, which was fired before either the UK Atomic Weapons Research Establishment at Aldermaston had issued safety regulations or the Australian Safety Committee had been formed, and whose plume is incriminated as the "black mist" of aboriginal lore, was safe, the committee concludes. It was after tracking the clouds of Totem 1, too, that aircraft contaminated with radioactivity were not isolated or treated for at least five days. Totem 1, the report concedes, may have exceeded current ICRP recommendations but "if that limitation was in fact exceeded, the excess would have been small and there would be no detectable effect on persons" Moreover, "a limited number of air crew may have been exposed to transient concentrations of radioactive substances exceeding the derived levels recommended for continuous exposure over a 13-week period, but not to total radiation exposures in excess of the recommended limits".

The conclusions relating to radiation exposure were based on records of readings from personal radiation monitoring devices. It has, howcver, been alleged in the past few months that dosimeters were faulty, that some personnel were not issued with film badges, that badges were issued but not processed, that some personnel were lax about wearing them and that some badges turned black and could not be read. In these circumstances, the recorded levels would not be relevant, especially because in the 1950s the policy was not to issue badges unless "specific exposure was likely to be a substantial fraction of prescribed limits".

The aboriginal claim that a "black mist", at the time of Totem 1 led to diarrhoea and death was dismissed by AIRAC on the grounds that the stories were inconsistent, perhaps provoked by patrol officers explaining the nature of nuclear tests. The committee also noted that there was a contemporary measles epidemic.

But the issue of nuclear tests in the Southern Hemisphere is still controversial.

Australia has expressed strong indignation at the second of this year's round of French nuclear tests in the tiny atoll of Mururoa in the South Pacific. What the government had been led to believe would be a "trigger device" turned out to be a 70 kilotonne explosion. The last Labor government successfully prosecuted France at the International Court of Justice, but the tests merely went underground. $\mathrm{Mr}$ Bob Hawke, the Prime Minister, is expected to protest in person when he meets President François Mitterrrand of France in Paris later this month.

Vimala Sarma

\title{
American Geophysical Union
}

\section{Are nuclear test bans verifiable?}

\section{Baltimore}

A SERIES of talks and a panel discussion at last week's meeting of the American Geophysical Union (AGU) provided a cross-section of seismological opinion on two central issues relating to a possible Comprehensive Test Ban Treaty (CTBT). First, have the United States and Soviet Union complied with the $150 \mathrm{kT}$ threshold imposed by the Threshold Test Ban Treaty in 1976? The answer seemed to be: yes for the United States, impossible to say for the Soviet Union given uncertainties in the seismological evidence. Second, would a CTBT be seismologically verifiable? The answer depends not only on the ability to discriminate between earthquakes and explosions but on the presence of monitoring arrays in the Soviet Union.

The AGU discussion was prompted by the Reagan Administration's indifference to current test ban negotiations. All US and Soviet tests have been conducted underground since the limited Test Ban Treaty was ratified in 1963. Although the threshold treaty was not ratified, the United States and Soviet Union undertook to abide by it. The United States, the Soviet Union and the United Kingdom also discussed a comprehensive test ban, but the Carter Administration withdrew in 1980 following the Soviet incursion into Afghanistan. The United States now argues that (1) seismic verification techniques are insufficiently reliable; (2) the Soviet Union may have repeatedly exceeded the $150 \mathrm{kT}$ threshold since 1976; (3) there is a need for continued testing.

The most pessimistic views were expressed by Drs T. C. Bache and R. W. Alewine of the Defense Advanced Research Projects Agency. Dr Alewine, assessing seismic estimates of Soviet test yiclds, concluded that the evidence was consistent with Soviet violation of the $150 \mathrm{kT}$ threshold on several occasions since 1976. He acknowledged that a geophysical explanation is possible, but emphasized that inoperability of treaty protocols on data exchange did not permit investigation of that possibility. But his estimates were challenged by other speakers. For instance, Professor I,ynn Sykes (Lamont-Doherty (ieological Observatory) said that too much attention had been given to body waves ( $P$ waves) and that surface (Rayleigh or $S)$ waves, the attenuation of which is less variable from one region to another, indicate Soviet compliance with the threshold treaty.

Sykes and others described empirical relationships between surface and body wave magnitudes on the one hand and test yields on the other using data from tests at the Nevada test site. A crucial element in the dispute is the correction for body wave attenuation needed when using such relations for Soviet tests at the site at Semipalatinsk. During the panel discussion, E. Herrin (South Methodist University) claimed that, given the uncertainties, one could say with conviction only that maximum Soviet yields were greater than $75 \mathrm{kT}$ and less than $300 \mathrm{kT}$.

Body-wave corrections are also important in discriminating between explosions and earthquakes - essential of test ban verification. Underground explosions produce a larger proportion of seismic energy in the form of body waves (as opposed to surface waves) than do earthquakes. However, the attenuation correction for body waves needs to be relatively large (a few tenths of a magnitude) to ensure that earthquakes and explosions form distinct statistical populations within this criterion. T. W. Bache emphasized such problems and maintained that they, together with practical problems of assessing huge volumes of data, render verification impossible. Other participants (particularly J. Evernden of the US Geological Survey) attacked Bache's adherence to a zero correction for body-wave attenuation.

Sykes mentioned a difficulty associated with the lowering of the test threshold. 150 $k T$ devices are exploded at depths that ensurc a hard rock surrounding. But small explosions could be fired above the water table in soft rock, which would reduce by an injeterminable amount the energy coupled into seismic waves. However, Evernden surveyed the uses of depth, location and frequency spectra as seismic discriminators and expressed the view that, provided that non-seismic monitoring techniques were also available, discrimination was always possible. Philip Campbell 